\title{
Can ozone be used as antimicrobial in the dairy industry? A systematic review
}

\author{
R. B. Afonso, ${ }^{1,2 *}$ R. H. R. Moreira, ${ }^{2}$ and P. L. R. de Almeida ${ }^{3}$ \\ ${ }^{1}$ Paulista Society of Veterinary Medicine, São Paulo, SP, 03077-000, Brazil \\ ${ }^{2}$ Postgraduate Program in Animal Production, Federal Rural University of the Semi-Arid UFERSA, Mossoró, RN, 59625-900, Brazil \\ ${ }^{3}$ Department of Applied Statistical Biometrics, Rural Federal University of Pernambuco, Recife, PE, 52171-900, Brazil
}

\section{ABSTRACT}

Milk and dairy products are abundantly consumed in all cultures, but unprocessed products can harbor pathogenic microorganisms that can cause serious health risks for its consumers. To avoid this, it is necessary to process the products. Ozonation is a clean technique that has antimicrobial power due to its oxidation potential, reducing the microorganisms and limiting the production of enzymes, but the effectiveness of ozone treatment can be affected by the temperature, $\mathrm{pH}$, additives, humidity, and the amount of organic matter around the cells. The goal of this systematic review was to analyze whether the use of ozone could improve the microbiological quality of dairy products and whether it could be used as an antimicrobial technique. Six databases (PubMed, Scielo, CAPES, Science Direct, Science Core Collection, and PLOS) were used in this research, with 2 independent reviewers selecting articles up to November 21, 2020, with experiments that used ozone as an antimicrobial in dairy products. A total of 731 articles were found, but only 9 were selected. The remainder were excluded according to the following criteria: was not related to the main theme; was a review; did not contain microbiological analysis; did not mention the concentration of gas and time of the ozone treatment; and was not an experiment. Important points were noted in quality criteria, which resulted in the need to standardize the methodology applied in research to improve the quality of the experiments. Studies were carried out with many different samples of milk, but the best results in reducing the microorganism count were obtained from samples containing low levels of fat.

Key words: ozone, ozonation, milk, dairy, systematic review

Received June 21, 2021.

Accepted October 6, 2021.

*Corresponding author: afonsomedvet@gmail.com

\section{INTRODUCTION}

Milk is consumed worldwide, being a complete nutrient source of high biological value, with water, protein, carbohydrates, fat, vitamins (A, D, E, K, and C) and minerals (Marangoni et al., 2019). Milk and dairy products can be found at any grocery store, and most need to be kept refrigerated. The conservation of these products is important, because they can be a substrate for the growth of microorganisms.

Raw milk can have some pathogens with habitats in food-producing animals, which can cause serious risk for the consumer health (Fusco et al., 2020). Today, the most common processing method of raw milk is pasteurization or UHT treatment; both use temperature to decrease the number of pathogenic microorganisms, but the second method results in a commercially sterile product (US Food and Drug Administration, 2020a).

According to Genecya et al. (2020), ozone is triatomic oxygen composed of free radical oxygen in addition to molecular oxygen. It has antimicrobial power due to its oxidation potential, reducing microorganisms count, as well as limiting enzyme production during a storage phase. The process of inactivating microorganisms by ozonation is complex once the compound reacts with several bacterial cellular constituents such as proteins and peptidoglycan from the capsule of spore walls and against the viral capsule. Ozone reacts with unsaturated lipids, proteinase, respiratory enzymes in cell membranes, enzymes, and nucleic acids in the cytoplasm. Ozone's antimicrobial effectiveness can be affected by temperature, $\mathrm{pH}$, additives, humidity, and the amount of OM around the cells (Pirani, 2011). Ozone treatment can be used in gaseous or in aqueous phases in food processing, and many studies have pointed out the antimicrobial power with several microorganisms, including gram-positive and gram-negative bacteria, even as spore forms and vegetative cells (Brodowska et al., 2018).

In addition to these positive points about ozone, its use has small residual effect with a short life, because the $\mathrm{O}_{3}$ quickly decomposes into $\mathrm{O}_{2}$, and that has a 
great value in the world market for companies looking for green and sustainable technologies (Pandiselvam et al., 2019). According to Pimonenko et al. (2020), consumers are changing their behavior and choosing products generated with green and sustainable technologies, helping to cope with the environmental issues. Consequently, the revolution of the eco-friendly lifestyle by consumers forces companies to renew and review their technologies.

The US Food and Drug Administration code 21CFR173.368 mentions the permission for using ozone directly in foods in its gaseous or aqueous phase (US Food and Drug Administration, 2020b). This legislation is important because it already allows the use of this technology in food industries, but more studies are required regarding gas concentrations and exposure time for each type of food to result in a product free of pathogenic microorganisms.

Experiments with milk have some specific procedures due to its OM, which can affect the efficiency of ozone. In fact, there are few studies in this field and no systematic reviews. Thus, the aim of this study was to search experiments that used ozone in milk and included microbiological analysis to show objectively whether ozone can be used as an antimicrobial in the dairy industry.

\section{MATERIALS AND METHODS}

\section{Date Sources and Search Strategy}

The study based itself in PubMed, Scielo, CAPES, Science Direct, Science Core Collection, and PLOS databases were searched for relevant published studies with no year restriction and using terms in English. The search terms were based on use of ozone in milk studies: (1) "ozone" AND "milk", (2) "ozone" AND "dairy", (3) "ozonation" AND "milk", (4) "ozonation" AND "dairy". The terms were used in the abstract, title, and key words. The search ended on November 21, 2020.

\section{Study Selection}

Two independent investigators searched the literature and examined all relevant studies for inclusion. The main goal of the research was to find studies that used ozone in milk or dairy products with the aim to improve the microbiological characteristics. The first attempt to identify articles was by the title, and the second was by complete text reading. The exclusion criteria for systematic review were as follows: (1) was not related to the main theme; (2) was a review; (3) did not contain microbiological analysis; (4) did not mention the concentration of gas and time of the ozone treatment; and (5) was not an experiment.

\section{Data Extraction}

In all texts, 2 reviewers collected basic data, variation sources, and microbiological analysis. Basic data included identification, title, first author, year of publication, publication journal, publisher, and impact factor from the year 2020. Variation sources included replication of ozone treatment, type of sample, equipment, type of oxygen, gas flow rate, ozone treatment, ozone concentration, and ozonation time and temperature.

Data were collected from the articles to make the quality criteria ranking shown in Table 4, by assigning points for each item of relevance to the study, allowing characterization of articles and reliability. Observed items included replication of the ozone treatment; replication of microbiological analysis; mention of the temperature of the gas, sample, storage, and room ambient temperature; studies with a control group; observed initial inoculums at sample; flow rate of gas and type of oxygen; and result in numbers. The points were distributed in the following way: those fulfilling the requirements would score points, and those that did not report it (no information) would score zero points, resulting in higher scores for experiments with more cited information. The results of the reductions in microbiological counts after ozone treatment were the object of the discussion session showing the best results of each experiment.

\section{RESULTS}

\section{Search and Selection of Studies}

The initial search in the databases resulted in 731 records, 456 of which were duplicates, and 21 studies were selected to be read entirely. Nine articles matched the criteria, and this total number is small, but because there are not many experiments on a global scale according to the search, these data can be representative. Table 1 shows the key words and respective data sources.

From the selected studies, basic data and variable data were collected according to Tables 2 and 3. Basic data included information about the authors, year of publication, journal, publisher, and Impact Factor (IF) in 2020, which was found on the publishers' websites. More than half of the studies were published in 2017, and the oldest was published in 2007. Elsevier published 4 of the articles collected, and Springer published 2. For IF, the year of choice was 2020 for all; 3 of the 
Table 1. Data source, key words, and results of papers evaluated for the systematic review

\begin{tabular}{lcccrr}
\hline & \multicolumn{5}{c}{ Key words } \\
\cline { 2 - 4 } Database & $\begin{array}{c}\text { Ozone } \\
\text { and milk }\end{array}$ & $\begin{array}{c}\text { Ozonation } \\
\text { and milk }\end{array}$ & $\begin{array}{c}\text { Ozonation } \\
\text { and dairy }\end{array}$ & $\begin{array}{c}\text { Ozone } \\
\text { and dairy }\end{array}$ & Total \\
\hline Scielo & 1 & 0 & 3 & 3 & 7 \\
Capes & 22 & 4 & 8 & 35 & 69 \\
PloS & 0 & 0 & 0 & 0 & 0 \\
Pubmed & 38 & 38 & 48 & 48 & 172 \\
Science Direct & 38 & 38 & 31 & 31 & 138 \\
Science Core Collection & 130 & 23 & 29 & 163 & 345 \\
\hline
\end{tabular}

journals had an IF $>4$, with the highest 6.291 , 4 had IF between 2.476 and 3.032 , the lowest IF was 0.564 , and one journal had no information about IF.

Table 3 has information about the experiment, including type of oxygen used to transform in ozone, flow rate of the ozonation, type of ozone treatment, and binomial (ozone concentration/exposure time). The type of ozone treatment changed according to the sample; the study of Alexopoulos et al. (2017) used ozone in the brine for feta cheese and on the surface of yogurt. The conditions comprise ozone concentration $(\mathrm{mg} / \mathrm{L})$ and ozonation time (min). No researcher used the same ozone concentration; more than half of the experiments used only one concentration, whereas 3 applied 2 combinations, and 1 chose 3 combinations. Regarding the time of ozonation, 5 studies used more than 4 combinations of time, and the rest used 3 combinations.

Regarding the types of samples, most researchers used fluid milk with different levels of fat and lactose. Whether the milk was homogenized or not also entered as a parameter for some authors. Almost all studies were carried out with just fluid milk; Hwang et al. (2007) used frozen milk, Alexopoulos et al. (2017) used yogurt and feta cheese, and Sert et al. (2020) used raw cream. There are 2 studies with Escherichia coli, 2 with Streptococcus, 3 with total mesophilic counts, 2 with mold and yeast, and the others have different microorganisms. Some experiments evaluated the effectiveness of ozone in more than one microorganism. Four of the researchers chose to use graphics to point out the results of the analysis.

\section{Quality Criteria}

The work with the highest quality score was 16 by Mohammadi et al. (2017), and the lowest was by Torlak and Sert (2013) with 4 points; $44 \%$ of studies scored between 12 and 16 .

\section{DISCUSSION}

The elaboration of the key words was based on the reading of many studies concerning dairy with the utilization of ozone to improve the quality of the products and the choice of the databases was by relevance. The IF of each journal has elevated value in the scientific chain to evaluate the importance or rank of a journal, and this points to high quality standards of the conducted works.

As shown in Table 3, some authors did not mention the type of oxygen or the flow rate of the gas. These points must be considered to systematize or compare

Table 2. Basic data of the selected articles used in the systematic review

\begin{tabular}{|c|c|c|c|}
\hline Author & Journal & Publisher & $\begin{array}{c}\text { Impact factor } \\
(2020)\end{array}$ \\
\hline Sert et al., 2020 & Food Science and Technology & Elsevier & 4.952 \\
\hline Munhõs et al., 2019 & XXVI Brazilian Congress on Biomedical Engineering & Springer & $\mathrm{NI}^{1}$ \\
\hline Alsager et al., 2018 & Ecotoxicology and Environmental Safety & Elsevier & 6.291 \\
\hline Alexopoulos et al., 2017 & International Journal of Food Microbiology & Elsevier & 5.277 \\
\hline Mohammadi et al., 2017 & The Journal of the International Ozone Association & Taylor \& Francis & 2.562 \\
\hline Hwang et al., 2007 & Asian-Australasian Journal of Animal Sciences & Ajas & 2.539 \\
\hline
\end{tabular}

${ }^{1} \mathrm{NI}=$ no information. 
Table 3. Description of treatment variables in the experiments described in the systematic review

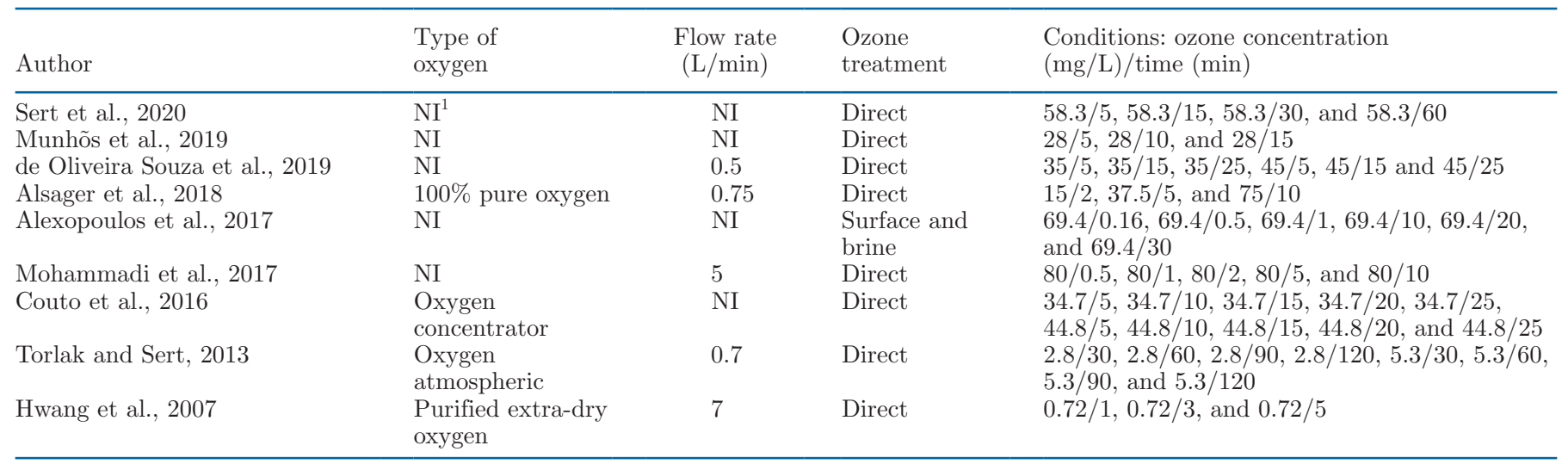

${ }^{1} \mathrm{NI}=$ no information.

the techniques used in the experiments, improving the quality of the studies. In addition, there is a need to standardize measures to avoid errors; the most-used unit for ozone concentration was milligrams per liter, and one study using parts per million. Panta et al. (2020) affirms that the flow rate can directly affect the production of ozone.

A few articles report 1 replication or no information on the number of replications, whereas others report 3 replications (Table 4), indicating a lack of standardization between experiments. From this point onward, it is necessary to improve the methodology of these analyses bringing an authentic number of repetitions and, on the other hand, even with no information or 1 replication, the authors published the studies in journals with a high IF, as shown in Table 2. When replications are applied to experiments, the results are more reliable; if there are fewer replications, the results are less compelling and need to be treated with caution (Plucker and Makel, 2021).

The studies described samples with different milk compositions, such as whole milk, skim milk, homog-

Table 4. Quality criteria used to evaluate the studies analyzed in the systematic review ${ }^{1}$

\begin{tabular}{|c|c|c|c|c|c|c|c|c|c|}
\hline Criterion & $\begin{array}{l}\text { Sert } \\
\text { et al., } \\
2020\end{array}$ & $\begin{array}{l}\text { Munhõs } \\
\text { et al., } \\
2019\end{array}$ & $\begin{array}{c}\text { de Oliveira } \\
\text { Souza et al., } \\
2019\end{array}$ & $\begin{array}{l}\text { Alsager } \\
\text { et al., } \\
2018\end{array}$ & $\begin{array}{l}\text { Alexopoulos } \\
\text { et al., } \\
2017\end{array}$ & $\begin{array}{l}\text { Mohammadi } \\
\text { et al., } \\
2017\end{array}$ & $\begin{array}{l}\text { Couto } \\
\text { et al., } \\
2016\end{array}$ & $\begin{array}{c}\text { Torlak } \\
\text { and Sert, } \\
2013\end{array}$ & $\begin{array}{l}\text { Hwang } \\
\text { et al., } \\
2007\end{array}$ \\
\hline $\begin{array}{l}\text { Replication of ozone } \\
\text { treatment }\end{array}$ & 3 & 3 & 3 & 1 & 1 & 3 & 1 & 0 & 3 \\
\hline $\begin{array}{l}\text { Replication of } \\
\text { microbiological } \\
\text { analysis }\end{array}$ & 3 & 0 & 3 & 0 & 3 & 3 & 3 & 0 & 3 \\
\hline Storage temperature & 1 & 0 & 0 & 0 & 1 & 1 & 1 & 0 & 1 \\
\hline $\begin{array}{l}\text { Room ambient } \\
\text { temperature }\end{array}$ & 1 & 1 & 1 & 1 & 0 & 1 & 0 & 1 & 1 \\
\hline Control group & 1 & 1 & 1 & 1 & 1 & 1 & 0 & 0 & 1 \\
\hline Initial and final count & 1 & 1 & 1 & 0 & 1 & 1 & 1 & 1 & 1 \\
\hline Flow rate & 0 & 0 & 1 & 1 & 0 & 1 & 0 & 1 & 1 \\
\hline Type of oxygen & 0 & 0 & 0 & 1 & 0 & 0 & 1 & 1 & 1 \\
\hline
\end{tabular}

${ }^{1}$ Replication of ozone treatment: 1 replication of ozone treatment scored 1 point, 3 replications of ozone treatment scored 3 points and no information (NI) has zero points. Replication of microbiological analysis: 3 replications of microbiological analysis scored 3 points, and NI has zero points. Temperatures: mention of gas temperature scored 1 point, mention of sample temperature scored 1 point, mention of storage temperature scored 1 point, mention of room ambient temperature scored 1 point, and NI has zero points. Control group: studies with control group scored 1 point, studies with no control group or NI has zero points. Initial and final count: mention initial and final count of the microorganism before and after ozone treatment scored 1 point and NI has zero points. Flow rate: note of flow rate of gas scored 1 point and NI has zero points. Type of oxygen: mention the type of oxygen scored 1 point and NI has zero points. Result in numbers: results of analysis in numbers and not just graphics scored 1 point, and results in graphics only have zero points. 
enized, unhomogenized, lactose-free skim milk, lactosefree whole milk, UHT milk, whole milk powder, skim milk powder, and fresh milk. It is important to have research with different levels of OM; according to Pirani (2011), OM can compete with microorganisms for ozone, because initially it oxidizes the elements of the substrate, and then the bacterial cells. Other factors such as $\mathrm{pH}$ and temperature can alter reactivity and antimicrobial efficacy. Nevertheless, in general, ozone is more stable at low than at high $\mathrm{pH}$ values, and a temperature higher than that of refrigeration can increase ozone reactivity. Therefore, these annotations need to be present in published studies to ensure a better understanding of the changes in the environment related to study results.

Sensory analysis of milk before and after ozone treatment can improve the quality of the study, as treatment can result in sensory changes. In the experiment of Santos et al. (2016), the use of ozone at 5 and $10 \mathrm{mg} / \mathrm{L}$ with an exposure time of 30 min caused a pronounced change in the color of the milk sample, confirming the importance of sensory analysis of the product, as well as physical chemical analysis, because ozone can react with several cellular constituents such as microorganisms and milk components.

Milk or milk products are biodegradable, so maintaining refrigeration temperature is extremely important, as well as this information being referenced in the study. Milk spoilage can be affected by the initial microbial count and how these microbes can increase under particular storage conditions (Ziyaina et al., 2020).

Some studies chose to point out the results of the analysis in graphics, and that made it difficult to extract accurate data, so it is recommended to use tables with precise numbers. Graphics can facilitate the visualization but should be used in addition to the tables to improve comprehension of the data.

Alsager et al. (2018) used ozone to remove antibiotics in milk and mentioned only qualitative antimicrobial activity after the ozone treatment. The results showed that ozone is more efficient with faster rate constants, degrading $95 \%$ of the compounds.

According to de Oliveira Souza et al. (2019), ozone treatment against $E$. coli has better results in lactosefree skim milk with maximum reduction counts of 1.53 and $1.54 \log$ cycles, when adopting the binomials 35 $\mathrm{mg} / \mathrm{L}$ in $25 \mathrm{~min}$ and $45 \mathrm{mg} / \mathrm{L}$ in $25 \mathrm{~min}$, respectively. The results were different for homogenized whole milk with reductions of 0.29 and $0.39 \log$ cycle at the same binomials, respectively. The strain E. coli O157:H7 (ATCC 43890) was used and inoculated at approximately $10^{4} \mathrm{cfu} / \mathrm{mL}(3.0 \mathrm{~mL})$ of each sample of milk $(297 \mathrm{~mL})$ before ozonation.
Couto et al. (2016) also affirms that a better result was reached with skim milk, with the highest reduction of Staphylococcus aureus being $0.42 \log _{10}$ at the binomial $34.7 \mathrm{mg} / \mathrm{L}$ in $25 \mathrm{~min}$ and $44.8 \mathrm{mg} / \mathrm{L}$ in 25 min, but with the whole milk the maximum reduction was 0.19 and $0.21 \log _{10}$ at the same conditions. For an ozone exposure of $5 \mathrm{~min}$, there was no depletion in microbial load. In addition, Munhõs et al. (2019) noted that ozone treatment in skim milk has a better result in reduction of microbial count.

In one study about the shelf life of dairy products, yogurt samples treated with ozone at the binomial 69.4 $\mathrm{mg} / \mathrm{L}$ in $0.5 \mathrm{~min}$ had all spoiled with a delay of $5 \mathrm{~d}$ compared with the untreated samples, but these differences were not indicated with other binomials. In the same experiment but with feta cheese, no differences were observed after $60 \mathrm{~d}$ of storage compared with untreated samples (Alexopoulos et al., 2017). The use of ozone was not very effective in this experiment.

In the experiment of Mohammadi et al. (2017) with $3.2 \%$ fat milk, the control group had the highest psychrotrophic and mesophilic counts (6.68 and 5.87 log $\mathrm{cfu} / \mathrm{g})$, and the treatment ozone group had the lowest (5.68 and $4.71 \mathrm{log} \mathrm{cfu} / \mathrm{g}$ ) after $10 \mathrm{~min}$ of ozone exposure. The treatment with 5 min of exposure had no effect. This experiment used higher concentrations of ozone in shorter exposure times, resulting in little reduction in microorganism counts; the experiments with better results were characterized by longer exposure times.

With milk powder, the reduction in counts against Cronobacter were 2.71 and $3.28 \mathrm{log}$ cycle (skim milk powder and whole milk powder, respectively) at the binomial $5.3 \mathrm{mg} / \mathrm{L}$ in $120 \mathrm{~min}$; when this concentration was used for 30 and $60 \mathrm{~min}$, the results were not significant (Torlak and Sert, 2013). Ozone was more effective when used for longer exposure time on whole milk, and this result differs from other experiments that had better results on skim milk. It is difficult to compare because some samples were prepared with milk powder and others with fluid milk.

A study with raw cream to produce butter used ozone at $58.3 \mathrm{mg} / \mathrm{L}$ with a 30 - or 60 -min treatment, which completely inactivated coliform bacteria in butter samples. When other treatment times, 5 and $15 \mathrm{~min}$, the counts decreased by 2.45 and $3.50 \mathrm{log}$, respectively, and the control sample had $4.71 \mathrm{log} \mathrm{cfu} / \mathrm{g}$ (Sert et al., 2020). This result is curious, because the sample had a higher percentage of fat content compared with other studies and showed complete inactivation of bacteria, suggesting that ozone was completely effective and safe to use in cream of butter. On the other hand, there are few works available for better understanding the behavior of products with lipid matrix, affirming the need for more studies in the area to apply a standard. 
Hwang et al. (2007) did an experiment applying ozone treatment to freeze-concentrated milk and found that $12 \mathrm{~d}$ of storage was the upper limit without aseptic sterilization, and that pasteurized whole milk had a shelf life of 12 to $14 \mathrm{~d}$ if kept below $4^{\circ} \mathrm{C}$.

In some experiments with definite bacteria, trends were observed, probably due to the constituents of these microorganisms. The gram-negative bacteria (E. coli and Cronobacter) showed greater reductions in counts compared with gram-positive bacteria (Staph. aureus). This difference could be because of the percentage of peptidoglycan present around the wall of gram-positive bacteria. According to Malanovic and Lohner (2016), peptidoglycan with a multi-gigadalton molecular weight accounts for $90 \%$ of dry weight in gram-positive bacteria and $10 \%$ in gram-negative bacteria, and ozone initially oxidizes the substrate (peptidoglycan).

Because there are few studies in this area, it is important to point out relevant data in Table 4 . These criteria influence the quality and authenticity of research and thus, enable researchers to compare studies, seek improvements, and enhance the processing of milk by using ozone to ensure its wide use in the food industry. Moreover, the lack of studies seems to be a limiting factor because it is already clear that the technique is promising and eco-friendly; it is necessary to have more researchers in the field to carry out experiments so ozone may become a reality in milk and dairy industries.

\section{CONCLUSIONS}

The use of ozone treatment as an antimicrobial in milk or milk products can result in significant reductions in counts of microorganisms, showing it to be a promising and effective technique. Reduction in counts is more effective when the sample is exposed to ozone for longer periods. Products with less fat show better results with ozone treatment, but milk products, such as raw cream to produce butter, also showed good results. The results are positive but more studies on the technique that use a judicious high-quality methodology are required to affirm the combination of ozone concentration and treatment time are optimal for each type of product and to confirm that use of the technique, with different concentration and time combinations, in the dairy industry is safe.

\section{ACKNOWLEDGMENTS}

The Federal Rural University of the Semi-Arid (UFERSA), department of postgraduate program, located at Mossoró/RN (Brazil) provided sources of funding for the payment of publication. The authors have not stated any conflicts of interest.

\section{REFERENCES}

Alexopoulos, A., S. Plessas, Y. Kourkoutas, C. Stefanis, S. Vavias, C. Voidarou, I. Mantzourani, and E. Bezirtzoglou. 2017. Experimental effect of ozone upon the microbial flora of commercially produced dairy fermented products. Int. J. Food Microbiol. 246:5-11. https://doi.org/10.1016/j.ijfoodmicro.2017.01.018.

Alsager, O. A., M. N. Alnajrani, H. A. Abuelizz, and I. A. Aldaghmani. 2018. Removal of antibiotics from water and waste milk by ozonation: Kinetics, byproducts, and antimicrobial activity. Ecotoxicol. Environ. Saf. 158:114-122. https://doi.org/10.1016/j .ecoenv.2018.04.024.

Brodowska, A. J., A. Nowak, and K. Śmigielski. 2018. Ozone in the food industry: Principles of ozone treatment, mechanisms of action, and applications: An overview. Crit. Rev. Food Sci. Nutr. 58:2176-2201. https://doi.org/10.1080/10408398.2017.1308313.

Couto, E. P., E. R. Alencar, V. S. P. Gonçalves, A. J. P. dos Santos, J. L. Ribeiro, and M. D. A. Ferreira. 2016. Effect of ozonation on the Staphylococcus aureus inoculated in milk. Semin. Cienc. Agrar. 37:1911. https://doi.org/10.5433/1679-0359.2016v37n4p1911.

de Oliveira Souza, S. M., E. R. de Alencar, J. L. Ribeiro, and M. de Aguiar Ferreira. 2019. Inactivation of Escherichia coli O157:H7 by ozone in different substrates. Braz. J. Microbiol. 50:247-253. https: //doi.org/10.1007/s42770-018-0025-2.

Fusco, V., D. Chieffi, F. Fanelli, A. F. Logrieco, G. Cho, J. Kabisch, C. Böhnlein, and C. M. A. P. Franz. 2020. Microbial quality and safety of milk and milk products in the 21st century. Compr. Rev. Food Sci. Food Saf. 19:2013-2049. https://doi.org/10.1111/1541 $-4337.12568$

Genecya, G., I. S. Setiasih, and R. Andoyo. 2020. Effect of ozonation and pasteurization on total microorganism, $\mathrm{pH}$ and density whole milk and skim milk during cold storage. IOP Conf. Ser. Earth Environ. Sci. 443:012065. https://doi.org/10.1088/1755-1315/443/ $1 / 012065$.

Hwang, J. H., S. J. Lee, H. S. Park, S. G. Min, and H. S. Kwak. 2007. Comparison of physicochemical and sensory properties of freezeconcentrated milk with evaporated milk during storage. AsianAustralas. J. Anim. Sci. 20:273-282. https://doi.org/Https://doi .org/10.5713/ajas.2007.273.

Malanovic, N., and K. Lohner. 2016. Gram-positive bacterial cell envelopes: The impact on the activity of antimicrobial peptides. Biochim. Biophys. Acta Biomembr. 1858:936-946. https://doi.org/10 .1016/j.bbamem.2015.11.004.

Marangoni, F., L. Pellegrino, E. Verduci, A. Ghiselli, R. Bernabei, R. Calvani, I. Cetin, M. Giampietro, F. Perticone, L. Piretta, R. Giacco, C. La Vecchia, M. L. Brandi, D. Ballardini, G. Banderali, S. Bellentani, G. Canzone, C. Cricelli, P. Faggiano, N. Ferrara, E. Flachi, S. Gonnelli, C. Macca, P. Magni, G. Marelli, W. Marrocco, V. L. Miniello, C. Origo, F. Pietrantonio, P. Silvestri, R. Stella, P. Strazzullo, E. Troiano, and A. Poli. 2019. Cow's milk consumption and health: A health professional's guide. J. Am. Coll. Nutr. 38:197-208. https://doi.org/10.1080/07315724.2018.1491016.

Mohammadi, H., S. M. Mazloomi, M. H. Eskandari, M. Aminlari, and M. Niakousari. 2017. The effect of ozone on aflatoxin $\mathrm{M}_{1}$, oxidative stability, carotenoid content and the microbial count of milk. Ozone Sci. Eng. 39:447-453. https://doi.org/10.1080/01919512 .2017.1329647.

Munhõs, M. C., R. S. Navarro, S. C. Nunez, D. I. Kozusny-Andreani, and A. Baptista. 2019. Reduction of pseudomonas inoculated into whole milk and skin milk by ozonation. Pages $837-840$ in R. CostaFelix, J. C. Machado, A. V. Alvarenga, eds. XXVI Brazilian Congress on Biomedical Engineering, IFMBE Proceedings. Springer. https://doi.org/10.1007/978-981-13-2119-1_130

Pandiselvam, R., S. Subhashini, E. P. Banuu Priya, A. Kothakota, S. V. Ramesh, and S. Shahir. 2019. Ozone based food preservation: 
A promising green technology for enhanced food safety. Ozone Sci. Eng. 41:17-34. https://doi.org/10.1080/01919512.2018.1490636.

Panta, G. P., D. P. Subedi, H. B. Baniya, A. P. Papadaki, and S. Dhungana. 2020. An experimental study of co-axial dielectric barrier discharge for ozone generation. J. Nepal Phys. Soc. 6:84-89. https://doi.org/10.3126/jnphyssoc.v6i1.30554.

Pimonenko, T., Y. Bilan, J. Horák, L. Starchenko, and W. Gajda. 2020. Green brand of companies and greenwashing under sustainable development goals. Sustainability (Basel) 12:1679. https://doi .org/10.3390/su12041679.

Pirani, S. M. G. 2011. Application of ozone in food industries. PhD Thesis. Department VET/04, Inspection of Food of Animal Origin, University of Milan, Milan, Italy. https://doi.org/10.13130/ pirani-silvia-maria-gilda_phd2011-02-08.

Plucker, J. A., and M. C. Makel. 2021. Replication is important for educational psychology: Recent developments and key issues. Educ. Psychol. 56:90-100. https://doi.org/10.1080/00461520.2021 .1895796 .
Santos, A. J. P., J. L. Ribeiro, S. S. C. Poggiani, E. R. Alencar, and M. A. Ferreira. 2016. Avaliação da utilização de ozônio como método de beneficiamento de leite. Rev. Educ. Contin. Em Med. Veterinária E Zootec. CRMV-SP v. 14 n. 3 (2016), 94-94.

Sert, D., E. Mercan, and Ü. Kara. 2020. Butter production from ozone-treated cream: Effects on characteristics of physicochemical, microbiological, thermal and oxidative stability. Lebensm. Wiss. Technol. 131:109722. https://doi.org/10.1016/j.lwt.2020.109722.

Torlak, E., and D. Sert. 2013. Inactivation of Cronobacter by gaseous ozone in milk powders with different fat contents. Int. Dairy J. 32:121-125. https://doi.org/10.1016/j.idairyj.2013.05.013.

US Food and Drug Administration. 2020a. Code of Federal Regulations Title 21: Food and Drugs, 21CFR131.3.

US Food and Drug Administration. 2020b. Code of Federal Regulations Title 21: Food and Drugs, 21CFR173.368.

Ziyaina, M., B. Rasco, and S. S. Sablani. 2020. Rapid methods of microbial detection in dairy products. Food Control 110:107008. https://doi.org/10.1016/j.foodcont.2019.107008. 